\title{
The State of Art of Biological Processes in Paternal Care
}

\author{
Processos Biológicos na Paternidade: Estado de Arte
}

\author{
Rui Alexandre Nunes-Costa*, ${ }^{a}$, Bárbara Figueiredo ${ }^{a} \&$ Luis Moya-Albiol $^{b}$ \\ ${ }^{a}$ Universidade do Minho, Braga, Portugal \\ $\&{ }^{b}$ Universidade de Valência, Valência, Espanha
}

\begin{abstract}
This review of the state of art aimed to present the most recent data on neuronal, neurochemical, hormonal and genetic bases of paternal care using MEDLINE and PsycInfo databases (1970-2013). An integrated model of biological substrates that assist men in the transition to fatherhood is presented. Guided by a genetic background, hypothalamic-midbrain-limbic-paralimbic-cortical circuits were found to be activated in fathers when infant stimuli are presented. A set of specific neuropeptides and steroid hormones are produced and seem to be related to brain activation, potentiating the paternal phenotype. Together, genetic, brain and hormonal processes suggest the existence of biological bases of paternal care in humans, activated and enhanced by infant stimuli and responsive to variations in the father-infant relationship.

Keywords: Paternal care, neural activation, neurochemistry, genetic.
\end{abstract}

\begin{abstract}
Resumo
A presente revisão teve por objectivo apresentar o estado de arte dos dados mais recentes sobre as bases neuronais, neuroquímicas, hormonais e genéticas da paternidade, com recurso às bases de dados MEDLINE e PsycInfo (1970-2013). É apresentado um modelo de integração conceptual dos substratos biológicos que assistem os homens na transição para a parentalidade. Guiado por um background genético, circuitos neuronais hipotalámicos-mesencefálicos-límbicos-paralímbicos-corticais surgem ativados em pais quando lhes são apresentados estímulos infantís. Um conjunto de neuropéptidos e hormonas esteróides são também produzidos e relacionam-se com a activação neuronal, potenciando o fenótipo paternal. No seu conjunto, processos genéticos, neuronais e hormonais sugerem a existência de uma base biológica do comportamento paternal em humanos, activada e potenciada por estímulos infantís e responsiva a variações na relação pai-filho.

Palavras-chave: Paternidade, ativação neuronal, processos neuroquímicos, genética.
\end{abstract}

Kleiman and Malcom defined mammalian paternal care as "any increase in a pre-reproductive mammal's fitness attributable to the presence or action of a male" (1981, p. 348). Not being a restrictive definition of paternal care, Kleiman's and Malcom's definition applies to a range of possible direct and indirect behavioral actions performed by males and could be directly applicable to human behavioral repertoire.

Within the context of a monogamous social organization and biparental support of young, the transition to parenthood in humans in general involves all family members and presents important developmental tasks associated to profound changes at various levels of the individuals functioning (Figueiredo, 2004). When looking specifically to men, paternal care could be defined as what is done by an

${ }^{*}$ Mailing address: School of Psychology, University of Minho, Campus de Gualtar, Braga, Portugal 4710-057. E-mail: nunescosta@psi.uminho.pt

Acknowledgmet: This investigation is granted by Foundation for Science and Technology of Portuguese Government (SFRH/BD/76104/2011). adult male, which does not exist in the absence of descent and is directed to children in order to maximize their development, growth, welfare, and survival (Fernandez-Duque, Valeggia, \& Mendoza, 2009). Cross-cultural studies report that almost $40 \%$ of human cultures exhibit paternal care (Barry \& Paxson, 1971). The development of paternal behavioral repertoire could be divided into three stages (Benaches, 2010): the first, starts during the prenatal period which functions to help maturation, enabling the fetus to meet the demands of the outside world; the second, occurs during a brief period at birth when the parent has his first contact with his child; and the third, involves an extended period of time in which the father engages in monitoring, protecting and guiding of the offspring along its life cycle.

Although it is well known that behavioral changes are accompanied by biological changes in fathers as well as mothers, most studies on the transition to parenthood, fail to include the father and hence fail to describe all the processes and changes that fathers experience across this major life transition (Pleck, 2010). Moreover, those that do include the father tend to focus on the psychological 
and environmental changes and few include biological variables as important aspects of fatherhood transition. In fact, the first empirical studies to address the hormonal and neuronal changes in expectant fathers only appeared in the beginning of the last decade (Storey, Walsh, Quinton, \& Wynne-Edwards, 2000).

This article aims to present a review of the state of the art in the literature on neuronal, neurochemical, hormonal and genetic bases of paternal care. We seek to describe biological changes, presented as an integrated model of biological substrates that assist men in the transition to parenthood. MEDLINE and PsycINFO (1970-2012) databases were used, selecting the articles that seemed more adequate to the subject. 'Paternal care' expression was used to include behaviors (also referred as 'paternal behavior'), thoughts and/or emotions of males/men when directed to their offspring.

\section{Brain Functional Processes}

The foundational work for the study of brain substrates of parental care can be found in the extensive animal literature. Classical lesion studies in rodents have pointed out the medial preoptic area of the hypothalamus (MPOA), the bed nucleus of the stria terminalis (BNST), and the lateral septum (LS) as crucial brain areas for the onset and maintenance of the maternal behavior (e.g. Bosch, Pfortsch, Beiderbeck, Landgraf, \& Neumann, 2010) and paternal behavior (Parker, Kinney, Philips, \& Lee, 2001) in rodents.

In humans, the study of brain substrates of parenthood started in 1999 by Lorberbaum et al., with 4 participants (women), combining functional magnetic resonance imaging (fMRI) technique and presentation of infant auditory stimuli. The areas identified were consistent with the neuroanatomy of rodent maternal and paternal behavior and indicated greater activity of these areas (midbrain, hypothalamus, striatum, and septal regions) in breastfeeding first-time mothers in response to infant cry (Lorberbaum et al., 2002; Swain et al., 2003). In addition, there was greater activation in parents as opposed to non-mothers in the anterior cingulate and right medial prefrontal cortex. More recently, major studies combining fMRI technique and infant visual and/or auditory stimuli have identified several additional brain structures linked to human parental care, however, just very few have been focused on father's neural functioning.

Taking together all brain imaging studies, independent of the baby stimuli used, the gender of the parent or the time of assessment (weeks or months in the postpartum period), there is good evidence of a set of hypothalamicmidbrain-limbic-paralimbic-cortical neural pathways that act together to support parental behaviors and feelings in response to a variety of presented baby stimuli. Below we explore these areas in more detail, dissecting out aspects of the circuitry that are relevant to human paternal care.
Hypothalamus activation (Swain et al., 2003, Swain et al., 2004; Swain, Lorberbaum, Kose, \& Strathearn, 2007) could be understood as necessary for the "reflexive caring impulses" (Swain, 2008, p. 33), as addressed in animal models studies. Interestingly, and making an analogy with recognized data from animal studies, its role may be necessary for the onset and maintenance of some paternal behaviors through the release of gonadotropin-releasing hormone (GnRH). GnRH stimulates the pituitary gland to release some neuropeptides, and the luteinizing hormone, which could increases testosterone production. However, this hypothesis needs to be tested in humans.

The midbrain (periaqueductual gray), activated in most of these studies (Swain et al., 2003, Swain et al., 2004; Swain et al., 2007), contains dopaminergic projections, which are important for emotionally rewarding aspects of paternal care. Anterior cingulate activation (Swain, 2011; Swain et al., 2003, Swain et al., 2004; Swain et al., 2007), which is at the intersection between limbic and neocortex, may relate to rewarding processes generated by periaqueductual gray activation, as well as enhanced social attention and evaluation of infant stimuli and increased emotional arousal.

Limbic structures, namely the amygdala, were found to be strongly activated in mothers 2 to 4 weeks postpartum when gazing at their own baby photos (Ranote et al., 2004), and the same pattern of activation was also found with fathers while listening to their own baby cry (Seifritz et al., 2003). The amygdala's response in first-time parents could serve to accurately detect environmental threats (Phillips et al., 2004) and increase emotional vigilance (Davis \& Whalen, 2001), important in the first months postpartum to activate parents' preoccupations through baby signals in order to respond appropriately to their distress signals. When activated at the same time with insula (e.g. Seifritz et al., 2003), temporoparietal cortex (e.g. Swain et al., 2004) and anterior paracingulate area (e.g. Swain et al., 2004), the amygdala could play an important role in the capacity to explain others state of mind - theory of mind (Gallagher $\&$ Frith, 2003). Interestingly, the amygdala is innervated by oxytocinergic projections, which could modulate social approach behaviors (Domes et al., 2007).

The activation of subcortical memory structures (hippocampus formation) in both mothers and fathers during the postpartum period (Strathearn, Li, \& Montague, 2005; Swain et al., 2003; Swain et al., 2004) could be linked to long-term memory formation. The consolidation of long-term memories could allow the neural distinction between one's own baby and another person's baby which is important for parent-infant attachment formation (Swain et al., 2004). Furthermore, orbitofrontal cortex (OFC) is pointed to be related to positive attachment of parent and child and almost all of the imaging studies with new parents (Lorberbaum et al., 2002; Noriuchi, Kikuchi, \& Senoo, 2008), and some with fathers (Swain et al., 2003, Swain et al., 2004; Swain, Leckman, Mayes, Feldman, 
\& Schultz, 2005) found activation in this area and/or prefrontal adjacent areas (e.g. ventral prefrontal cortex, Swain et al., 2003). OFC activation could be interpreted as being implicated into parent's behavior and emotional control system. In other words, OFC activation could regulate, in long-term, parental worries and fear/anxiety, enhanced by limbic projections during infant stimuli as well as potentiate a satisfactory behavioral response to their infant's needs.

Fathers (Swain, 2011) displayed more activation in the areas stated above in the presence of infant stimulus (pictures, videos or cries) compared with neutral stimulus (white noise or images of houses). Also, significant differences between parental responses to own vs not-own infant visual signals were found (Ranote et al., 2004; Swain et al., 2007). These patterns of neural activation to baby stimulus seem to suggest that parents' brains are prepared to care for offspring, independent of the parents' gender.

Most of the studies developed to date did not focus on brain activation differences according to gender. However, when we look at father results in fMRI studies described above (e.g. Seifritz et al., 2003; Swain et al., 2004), men appear to activate the familiar set of brain regions as women. However, fathers' amygdala and basal ganglia activation were found to be relatively less pronounced compared to mothers' (Swain et al., 2007), which could reflect a higher preoccupation in the mother towards the baby (Swain et al., 2005).

Experience of caregiving also seems to shape parent's brains. Swain and colleagues (Swain et al., 2007), reported that, in presenting the same stimulus to primiparous mothers 2 to 4 weeks postpartum and 3 to 4 months after birth, amygdala and insular activations disappeared while medial prefrontal cortex, hypothalamic and cingulate responses appeared to be enhanced. At 3 to 4 months postpartum, the medial frontal cortex activity was higher than at 2-4 weeks postpartum. Based on those data, it suggests that brain activations to baby crying might change over several weeks postpartum. If at first weeks postpartum limbic influences were important to onset emotional arousal and preoccupations through baby signals to ensure an oriented and efficient response to his needs, by 3-4 months postpartum this is not so essential to its survival. A new pattern of activation of higher brain structures appears as the parent-infant relationship develops.

As we explore next, in terms of hormone release, fathers present the same pattern of hormone production as women across pregnancy and postpartum moments, but at a less striking level.

\section{Neurochemistry Processes}

At this point, little is known about neurochemical processes underlying paternal care. All of the studies are conducted with animal models of parenting, especially with dams. In humans, as stated above, a recent set of brain imaging studies clearly indicates that at least two neural systems underlie paternal care (Fernandez-Duque et al., 2009) which have a set of well-known neurotransmitters involved: one required for individual recognition and another emotional component that provides the reward for engaging with particular baby stimuli (e.g. Swain, 2011). Thus, crossing the knowledge obtained with animal models, we are able to speculate the involvement of at least one neurotransmitter (Dopamine) on the reward circuitry of paternal care. Serotonin has been shown to also affect paternal care.

Considering the wealth of evidence that exists in rodent models studies, Dopamine (DA) was found to be a critical role in motivation (Ostlund, Wassum, Murphy, Balleine, \& Maidment, 2011), reward system (Taber, Black, Porrino, \& Hurley, 2012), and on the onset of maternal behaviors in lactating rats (Afonso, King, Novakov, Burton, \& Fleming, 2011; Shahrokh, Zhang, Diorio, Gratton, \& Meaney, 2010). Although DA effects on maternal behavior are well established in females rats (eg. Afonso, King, Chatterjee, \& Fleming, 2009) studies that explore DA implications on paternal care are needed in order to clarify how this neurotransmitter acts in males. In fact, only one study with rodent males was conducted to examine the relationship of this monoamine with paternal behavior (Lonstein, 2002). The results showed subtle differences between sexes in the DA system functioning during parental care. After intraperitoneal injection of DA antagonist haloperidol in the biparental praire vole (Microtus ochrogaster) pup licking was decreased in both male and female parents and the latency to contact pups increased in males. Although being just one study with a specific rat specie and looking indirectly to DA system by haloperidol manipulation, this study seems to point that paternal care are more sensitive to DA levels than mother care.

Serotonin's (5-HT) influence on parental behavior has been studied with both pharmacological and lesion studies. Higher levels of 5-HT were found at medial preoptic area in juveniles rats, compared to adults when exposed to pups, suggesting 5-HT-maternal care relationship was probably affected by age of dams (Olazabal, Abercrombie, Rosenblatt, \& Morrell, 2004). Also important to state is the known involvement of 5-HT system with different components of parental behavior in animal models, as well as lactation (Nissen, Gustavsson, Widstorm, \& UvnäsMoberg, 1998), or oxytocin release in females and males (Saydoff, Rittenhouse, Van de Kar, \& Brownfield, 1991; Uvnäs-Moberg, Ahlenius, Alster, \& Hillegaart, 1996). It would be parsimonious to suggest that 5-HT mechanisms regulating parental care are conserved between the sexes and more importantly, those mechanisms may also function in humans. However, parental behavioral effects of 5-HT may be complicated to interpret in a simple cause-effect perspective. For example, Villalba and colleagues (Villalba, Boyle, Caliguri, \& De Vries, 1997) found 5-HT action on parental behavior in prairie voles, 
when pair-bonded voles were chronically treated with a selective 5-HT reuptake inhibitor. Fluoxetine-treated animals displayed a longer latency to exhibit parental responsiveness than did control (Villalba et al., 1997). Previous studies addressing the interaction between 5-HT and vasopressin found that fluoxetine reduces vasopressin secretion in animals (Ferris, 1996) and humans (De Bellis, Gold, Gercioti, Listwak, \& Kling, 1993), which is directly implicated on the onset of paternal behavior in humans (as we discuss elsewhere). That is, despite the evidence of 5-HT positive effect on parental behavior found in some studies, the interaction between 5-HT system with other biological systems may implicate at some level, incongruent results with animal models.

Depression is directly associated with lower levels of plasma and central 5-HT in humans during pregnancy (Lommatzsch et al., 2006), and also to the quality of mother-infant interaction (Murray, Halligan, \& Cooper, 2010). Depression is not exclusively to mothers and paternal depression is also reported (Figueiredo \& Conde, 2011). Since maternal and paternal depression are associated to fewer positive parent-infant interactions (Paulson, Dauber, \& Leiferman, 2006), and depression is associated to low levels of 5-HT, we hypothesize that this neurotransmitter could mediate the onset of paternal behavior, being however just a hypothetically assumption with empirical experimental needs.

\section{Neuroendocrinology Processes}

Despite the widespread evidence in animal studies of bi-parental species (e.g. Reburn \& Wynne-Edwards, 1999), it was only in April, 2000 that the first empirical study on the hormonal changes in expectant fathers was published (Storey et al., 2000). Since then, few studies have been dedicated to specifically study this phenomenon. However, there are already known changes in the pattern of production of some neuropeptide and steroid hormones during the transition to parenthood resembling neuroendocrine data collected with women in the same developmental transition.

Testosterone $(\mathrm{T})$ is a steroid hormone and is the principal male sex hormone. Nonhuman animal research with $T$ and paternal care raised the 'challenge hypothesis' which states that $\mathrm{T}$ levels vary according to male social context, increasing in reproductively contexts and decreasing when long-term bonds and paternal care emerged (Williamson, 2006). The extrapolation of this hypothesis for human $T$ studies have been piling up recently, making use of a wide range of methodological designs, salivary or plasma assessments, and samples of expectant or new primiparous fathers. In total, ten studies were published to date measuring plasma or salivary $\mathrm{T}$ levels with expectant or new fathers (Berg \& Wynne-Edwards, 2001; Fleming, Corter, Stallings, \& Steiner, 2002; Gettler, McDade, Feranil, \& Kuzawa, 2011; Gettler, McDade, \& Kuzawa, 2011; Ku- zawa, Gettler, Muller, McDade, \& Feranil, 2009; Storey, Noseworthy, Delahunty, Halfyard, \& McKay, 2011; Storey et al., 2000). Ulrike Ehlert team compared salivary T levels and relationship quality with partner between first-time fathers-to-be and control men in committed romantic relationships without children (Perini, Ditzen, Fischbacher, $\&$ Ehlert, 2012). Once again, 'challenging hypothesis' was confirmed once significantly lower $\mathrm{T}$ levels were found in fathers than in controls, as well as significant decreases in relationship quality (tenderness) from pre to post-natal period in fathers, but not in controls. Also, tenderness was partially moderated by $\mathrm{T}$ levels at pre-birth assessment. T seems to be influenced by father status and to influence romantic relationships quality.

Gettler and colleagues (Gettler, McDade, Feranil, et al., 2011; Gettler, Mcdade, \& Kuzawa, 2011) conducted the largest study in this field monitoring T salivary levels of 624 Philippine males for 4.5 years. Without any experimental procedure, by the second basal $\mathrm{T}$ assessment, men who became partnered fathers showed greatest declines in waking (-26\%) and evening (-34\%) T compared with single non-fathers. When they looked at the effect of paternal care on T levels, fathers who spent more hours of childcare had the lower T levels. Also, in an independent study, Anders and colleagues (van Anders, Tolman, \& Volling, 2011) observed that the presence of baby cues could influence the production of $\mathrm{T}$ in fathers saliva. Using a doll interaction paradigm they found that baby cries could induce decreases in $\mathrm{T}$ levels when coupled with dolls nurturing responses. As envisaged by 'challenge hypothesis', those studies point that $\mathrm{T}$ seems to mediate tradeoffs between mating and parenting in humans.

Another series of studies were more interested in understanding the salivary $\mathrm{T}$ changes across gestational period. All empirical data highlight a slight increase in the levels of this steroid hormone in the weeks before the birth (Berg \& Wynne-Edwards, 2001), followed by a decrease in the first weeks after birth (e.g. Storey et al., 2000). This hormonal pattern, where there is a decrease in testosterone levels of the parents after the birth of children, can be evolutionary justified by a decrease in aggression directed towards the offspring (Perrigo, Belvin, \& Vom Saal, 1991) and the need to search for mating opportunities (Clark \& Galef, 2000), allowing men to greatly focus on the quality of paternal care and to develop an emotional bond with their children (Clark \& Galef, 1999).

Cortisol (Cort) is known as the preeminent stress hormone in humans. In the presence of physiological or psychological stressors, the Hypothalamic-Pituitary-Adrenal axis (HPA) is activated and a cascade of molecular events ultimately induces glucocorticoids (Cort in humans) production at the cortex of adrenal glands. Cort is a pluripotent hormone acting in different tissues regulating many aspects of metabolism, growth and other immunological functions (e.g. Beishuizen \& Thijs, 2003; Cerqueira, Mailliet, Almeida, Jay, \& Sousa, 2007). 
Animal and human studies have shown that Cort has a significant role in social affiliation behaviors, being implicated in the formation of social bonds between pairs and parent-child emotional bond (e.g. Carter, 1998; Gonzalez, Jenkins, Steiner, \& Fleming, 2012) experience of paternity, the levels of free salivary Cort of expectant fathers increase in the last week before delivery, which might probably be linked to the anxiety experienced by the arrival of offspring and developmental tasks associated with it (Berg \& Wynne-Edwards, 2001). After delivery, the Cort levels decrease and are significantly lower than in non-fathers (Berg \& Wynne-Edwards, 2001, 2002; Fleming et al., 2002). However, these results change when the salivary collections are not performed at home and are accompanied by other experimental intrusive procedures that may threaten the paternal care of the baby (Storey et al., 2000). Thus, it can be concluded that the levels of cortisol, close to what happens in the mother-infant interaction, also has implications for the establishment of an effective paternal behavior.

Recently, Gettler and colleagues (Gettler, McDade, \& Kuzawa, 2011) reinforced the hypothesis of Cort role in men's parenting effort. Mating-oriented men were more likely to have higher salivary Cort and $\mathrm{T}$ compared to parenting-oriented men. Interaction with toddlers was found to decrease Cort levels in a $30 \mathrm{~min}$ father-baby interaction experimental procedure, being experienced fathers (non-primiparous) those with the greatest decrease (Gettler, McDade, \& Kuzawa, 2011). The same effect of infant contact in salivary Cort levels was found in a recent study of Storey and colleagues (Storey et al., 2011). In this study fathers were tested in a 30-minutes father-child interaction on a day when they were away from their toddlers for several hours before the experiment or in a day when they remained with their child throughout the day. Cort levels decreased in both experimental conditions but those levels were more salient with those fathers who spent more time with the baby before interaction. Taken together, those results suggest the importance of quantity and quality of father-infant contact on Cort levels as well as the role of this hormone in father-infant bond formation. As described elsewhere, the father-child interaction may 'program' aspects of infant's response to stress later in life and potentiate his/her optimal biological and psychological development.

Prolactin $(\mathrm{Prl})$ is a peptide hormone and has many effects including, for example, lactation regulation (Charoenphandhu, Wongdee, \& Krishnamra, 2010), sexual gratification after sexual act (Granata, Pugni, Rochira, Zirilli, \& Carani, 2012), proliferation of oligodendrocyte precursor cells (U.S. Patent No. 20120064028, 2012), or decreasing normal levels of sex hormones (Granata et al., 2012). Prl also appears to be involved in paternal care in a variety of species (Wynne-Edwards, 1998; Ziegler \& Snowdon, 2000).

Of all the hormones that have been studied in relation to the transition to fatherhood, either in humans or animals,
Prl is the one that most clearly shows the importance of hormones in the onset and maintenance of paternal care (Schradin \& Anzenberger, 1999). Fathers' peripheral prolactin concentrations increase significantly in the first weeks that follow the birth of their first child (Storey et al., 2000). High levels of this hormone allow fathers to be more alert and respond more positively to the cry of his children (Fleming et al., 2002). Plasma Prl was related to coordinated exploratory play between father and 6 months child and show high individual stability across time when first-time fathers were visited 2 and 6 months after birth, (Gordon, Zagoory-Sharon, Leckman, \& Feldman, 2010a, $2010 \mathrm{~b}$ ), maintaining high values even after fathers were away from their children for a day (Storey et al., 2011).

Progesterone (P4) is an essential hormone in the female physiology because of their importance to the ovulatory cycle and process of reproduction (Ellison \& Ellison, 2009). Supported by animal studies (e.g. Numan \& Insel, 2003), P4 have also been found to influence the expression of maternal behavior in many mammalian species. Despite its role on maternal behavior, the literature on $\mathrm{P} 4$ and male psychobiology is surprisingly sparse. In rodent studies, P4 findings with male samples are unclear. P4 was found to increase from pre- to post-partum in males of a hamster species (Schum \& Wynne-Edwards, 2005), but in other studies in other species of rodents this hormone was found to be lower in fathers compared with non-fathers (Trainor, Bird, Alday, Schlinger, \& Marler, 2003).

In humans, there is recent evidence that $\mathrm{P} 4$ have anxiety-reducing effects (Childs, Van Dam, \& Wit, 2010; Wirth, 2011) and may be also implicated in the promotion of social affiliation or positive social contact with conspecifics (Wirth, 2011). In the context of paternal care, to date only one study has studied the relationship between P4 and father-infant engagement (Gettler, Mcdade, Agustin, \& Kuzawa, 2013). Forty-four fathers played with their toddlers using a medium-sized plastic ball while three salivary samples were collected (baseline, 40 and 70 minutes after the interaction). Despite interactions between P4 other hormones found in this study being relevant data, in our point of view the most interesting results are those about greater P4 values found with fathers who reported feeling happy/relaxed following the interaction and the fact that fathers of infants showed a greater 40 min decline in P4 compared with fathers of older children. These data is consistent with other results in the filed (discussed ahead in this article) suggesting that men's paternal experience and caregiving history alter their hormonal production. A better understanding of the relationships between $\mathrm{P} 4$, paternal care, and other hormones could lead to better understand of transition to fatherhood.

The neurohypophysial hormone Oxytocin (OT), a small nonapeptide, has a long established role at the moment of birth, providing uterine contractions and milk ejection (Russell \& Leng, 1998). However the role of the OT in mammals' behavior phenotype is much wider, having an important role in social bonds formation and 
anxiolytic effects during stressful events (Nunes-Costa, 2010). Looking into the behavioral phenotypic effects of OT, animal research demonstrated the key role of this neuropeptide in the development and maintenance of social cognition and social behavior (e.g. Carter, 1998).

The first study regarding OT levels in first-time fathers was published only in 2009 (Kuzawa et al., 2009). No differences were found between 'coresidential' fathers, 'visiting' fathers and non-fathers when urinary OT was assessed. However, more recent data about salivary (Feldman, Gordon, \& Zagoory-Sharon, 2010) and plasma (Feldman, Gordon, Schneiderman, Weisman, \& ZagoorySharon, 2010; Gordon et al., 2010a, 2010b) OT are explicit: there are no differences between maternal and paternal OT levels during the first postpartum weeks to 6 months postpartum, and there is a high time-stability in paternal OT; also OT mediates the quality of father-infant affect interaction (Uvnäs-Moberg, 1998).

To our knowledge there are no studies that assess expectant father's OT levels. However, it would not be surprising to find that OT increases during their partners' pregnancy, potentiating a future optimal set of paternal caregiving behaviors.

Elegant studies conducted on several animal species found that males tend to have higher vasopressin (Avp) levels than do females (e.g. Share, Crofton, \& Ouchi, 1988), being modulated by steroid hormones such as testosterone (Carter, 2007). It functions to increase blood pressure (Ducros et al., 2010) and acts as an antidiuretic (Liu et al., 2011). However, effects of Avp also extend to male social behavior, being implicated in rodent male aggression (Vogel et al., 2012) and bonding formation (Walum et al., 2008). Interestingly, receptors for AVP 1a are ubiquitously distributed through brain structures involved in reward/ dopaminergic pathways like ventral pallidum (Kuroda, Tachikawa, Yoshida, Tsuneoka, \& Numan, 2011). This interconnection between Avp and dopamine seems to enable "linking Avp response to social stimuli like mate or pup with positive emotional association" (Gray \& Anderson, 2010, p. 215). Transgenic experiments with rodents put in evidence this link between Avp and social behavior (e.g. Lim \& Young, 2006).

Only two studies have analyzed Avp in new fathers. The first empirical study was designed by Gray and coworkers (Gray, Parkin, \& Samms-Vaughan, 2007) with Jamaican fathers. They found that fathers and non-fathers did not differ on urinary Avp levels. However, the lower the age of their youngest child, the higher the Avp values found in fathers (Gray et al., 2007). The second and more recent study, previously described, also found that, among fathers, Avp levels were significantly and negatively correlated with the age of the youngest child (Kuzawa et al., 2009), but no group (fathers $v s$ nonfathers) differences were found for this neuropeptide. This study, like the Jamaican one, suggests a possible role of Avp in the father's response to baby stimuli and, namely in the formation of a social memory. Although those results implicated Avp in paternal responses, there are no studies that explore variations in Avp concentration as a function of stage of pregnancy with fathers.

Estradiol (Est) is the most potent estrogen in the class of steroid hormones. In the female, Est acts as a sexual hormone coordinating, for example, menstrual cycles and secondary sex characteristics. Neuroprotective functions (Behl, Widmann, Trapp, \& Holsboer, 1995), and prenatal sex dimorphism programming (Hulshoff et al., 2006) are also known as effects of Est actions. Est is also important for priming mammalian maternal behavior (Maestripieri \& Zehr, 1998; Rosenblatt, 1994).

Est influences on paternal care in men have not been as extensively studied as other hormones. Only one study in the last decade looked exclusively to Est variations in a father population. Berg and Wynne-Edwards (2001) documented low estradiol concentrations in saliva samples from control men, being undetectable in $43 \%$ of samples. However, estradiol was detectable in $68 \%$ of samples from men becoming fathers and the concentration increased from the last month of the pregnancy to the first month after the pregnancy. The lack of number of studies focussing on estrogen in fathers derives from the fact that estrogen levels are considerably lower in males than in females and may be often difficult to detect.

Although expectant or new fathers' hormone concentrations are lower than those found in women, data suggest a biological predisposition of men to care for their children. This biological contribution could allow for an increased likelihood of survival and growth of offspring and female fertility (Wynne-Edwards \& Timonin, 2007). In fact, some studies described above demonstrated that variations in some hormones relate to the variance in fathers' responses (e.g. Gordon et al., 2010b).

On the other hand, this paternal hormonal response in humans only increases or decreases the likelihood or intensity of paternal behaviors. In fact, animal studies (Rosenblatt, Olufowobi, \& Siegel, 1998) have shown that these set of care behaviors are primarily dependent on environmental and social stimuli. That is, variations on hormone levels are not causal in paternal behavior. Such variations are purposed to support paternal behavior, being "important for other challenges at the same time as fatherhood" (Wynne-Edwards, 1998, p. 114). Only in the presence of environmental stimuli that signal directly or indirectly the presence of offspring, hormonal changes occur which, ultimately, could increase or decrease the quantity/quality of care for the offspring. Some of the studies described above found this relationship between quantity parent-infant contact and the concentration increases of some hormones involved in paternal care (Feldman, Gordon, Scheiderman, et al., 2010; Storey et al., 2011). One study also attempted to identify the mother's biological cues which could influence hormonal concentrations in expectant fathers (Berg \& Wynne- 
Edwards, 2002). The researchers sought to demonstrate that pheromonal communication (olfaction) between partners might influence endocrine status in fathers since it could signal the presence of offspring and influence the neuroendocrine pathways of paternal behavior. The results showed a positive correlation only in the pre-delivery period between maternal cortisol levels and males testosterone and cortisol concentrations, and between female levels of testosterone and male cortisol concentrations, explaining $30 \%$ and $25 \%$ of the variance, respectively. Together, those results support the idea that environmental stimuli (from baby and mothers) are able to activate brain areas devoted to paternal care that favor certain neuroendocrine responses and subsequently, the quality of care to the baby (Corter \& Fleming, 2002).

\section{Genetic Processes}

Ethical and logistical constraints make knockout studies impossible with human samples. Those kinds of studies use genetically engineered mice in which an existing gene is inactivated (knocked out) causing changes in a mouse's phenotype. The most knowledge about molecular basis of maternal care derives from those studies with rodents and data is generalized, with caution, to human population. At least nine genes, encoding three protein transcriptional factors - FosB (Brown, Ye, Bronson, Dikkes, \& Greeberg, 1996), Peg3 (Li et al., 1999) and Fkh5 (Wehr, Mansouri, Maeyer, \& Gruss, 1997); three enzymes - Mest/peg1 (Lefebvre et al., 1998), Dbh (Thomas \& Palmiter, 1997) and nNOS (Gammie \& Nelson, 1999); two receptors ER $\alpha$ (Lubahn et al., 1993) and PrlR (Leckman \& Herman, 2002); and one neuropeptide - OT (Nishimori et al., 1996) have been identified to be necessary for the expression of maternal behavior. Being involved in the production of molecules that are also important for the male-infant caregiving onset or expressed in brain structures implicated in this relationship, those genes identified in maternal care studies are also probably allocated to paternal care. However, no studies were designed to date in order to test the association between those genes and the paternal behavior. The gene associated with vasopressin receptor 1a gene (AvpR1a) expression was the only one empirically tested in the association to pair-bonding and, indirectly, to paternal care. In a study conducted with voles, polymorphisms in the promoter region of vasopressin receptor 1a gene (AvpR1a) found to be able to alter the distribution and density of vasopressin receptors in brain tissue (Hammock \& Young, 2005), consequently changing Avp action on those brain structures and probably, the expression of father care. Although the attempt to find genetic basis of paternal care, the relationship between AvpRla and paternal care has not yet been directly tested, being those studies only correlational.

Studies of genetic influence on maternal behavior in mammals, mostly conducted with knockout rodents, suggest that the expression of paternal behavior could be imprinted on the individual genotype/governed by molecular events; moderated by brain structures and their development/activation; and by endocrinal functioning.

\section{Biological Bases of Paternal Care: Integration Model}

Based on brain imaging of human fathers, neuroendocrine studies of paternal care, and data collected in rodents' genetic studies, a model in an attempt to integrate all data about biological bases of fathers' responses to infant stimuli is presented (see Figure 1).

Sensory cortices integrate infant stimuli inputs, in form of sounds, visual, tactile or touch cues, and/or pheromone signals shared in the contact with pregnant women. Once organized and transduced to neural signals, this information obtained in the contact with offspring is transmitted to some brain areas (e.g. anterior cingulate, basal ganglia, periaqueductal gray) implicated on the evaluation of the rewarding aspects of stimuli (Noriuchi et al., 2008; Swain, 2008), at same time that a set of neurotransmitters (e.g. DA) start the communication between brains structures. Next, the information is forwarded to corticolimbic circuits (e.g. amygdala, insula, hypothalamus) that regulate high emotional responses, increasing the ability to respond rapidly to dangerous stimuli related to baby safety, and more activated in the first weeks postpartum (Swain, 2008). At this level, some hypothalamic nuclei are triggered and paternal hormonal production starts (e.g. Storey et al., 2000), also potentiated by a set of neurotransmitters (e.g. 5-HT). The function of this parallel system is to support the integration of the information collected until now (at this level or in higher levels of processing, e.g. at frontal cortex) and then uses that information to guide appropriate behavioral responses for baby demands (Gray \& Anderson, 2010). In addition, cognitive circuits regulating more complex behaviors and cognitions are activated (Swain et al., 2007). The elaboration of more complex and efficient behaviors is essential for baby survival and well-being. At this level, "reflexive, cognitive, and emotional modules" (Swain, 2008, p. 34) create the possibility to the elaboration of more coordinated and idiosyncratic responses, and the formation of attachment bonds with infant. Finally, sensoriomotor and prefrontal cortices develop behavioral responses, thoughts, emotions and hypothalamus physiological responses (e.g. increases of heart rate, 100). Paternal output enhances new baby inputs and the cycle repeats, activating the same or new brain areas (depending of baby responses), successively changing patterns of the brain activation in a recursive but modulating 'loop process'. A genotype background informing for the production of neuropeptides receptors (e.g. AvpR1) subserves all biological process, being also 'activated' by phenotype product. 


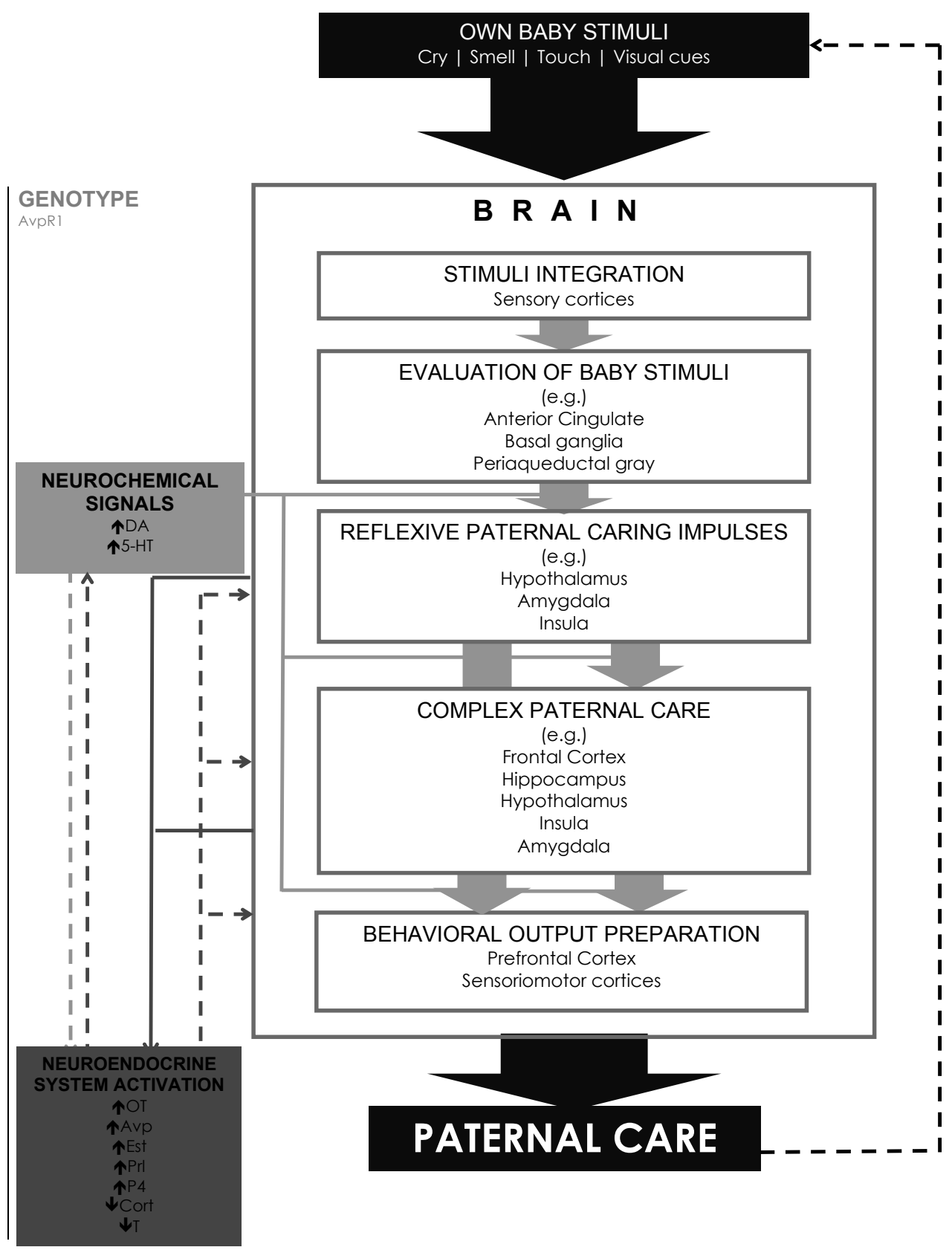

Figure 1. Integrative model of biological bias of paternal care.

\section{Final Remarks}

Taken together, brain image research with men suggests that networks of hypothalamic-midbrain-limbic-paralimbic-cortical circuits (O’Donnell, 2005; Swain, 2008; Williamson, 2006) that are activated in fathers' brain are highly specialized for baby stimuli, similar to those observed in women, and changes as the parent-infant relationship develops. This complex network of activation, from basal forebrain regions crucial to more primitive nurturing and caregiving responses, to higher structures necessary to handling emotions, motivation, attention, and empathy, are critical for an effective parenting response and critical for an infant's survival and optimal development (Swain, 2011).
However, based on brain imaging of fathers to this point one question emerges: what happens to fathers' brain during pregnancy? Once there were detected changes in patterns of some hormonal production during pregnancy, fathers' brain areas implicated in hormone production could also be sequentially activated before birth as the fetus stimuli and emotional evolvement with baby increases. More studies on neuronal programming of paternal care are required, making it interesting to explore expectant fathers' responses to baby stimuli through fMRI paradigms.

On the other hand, the diversity, and sometimes contradictory, data described on hormonal studies could be an echo of the multiplicity of methodologies implicated on hormone collection and detection (e.g. salivary vs 
blood vs urine collection; stimuli response $v s$ basal levels assessments). A helpful approach to this question would include studies that replicate methodologies and experimental designs used in previous studies. Also, Avp and OT patterns of production during pregnancy were not yet assessed with fathers and neurochemical information about paternal behavior is sparse and at times limited by ethic restrictions. More investigation with clinic populations (e.g. depressed fathers) could bring new data about the (disruption of) neurotransmitters systems of paternal care.

Evidence on a large number of rodent species strongly indicates that it is extremely unlikely that molecular mechanisms described previously are able to regulate such behaviors in humans (Fink, Excoffier, \& Heckel, 2006; Kentner, Abizaid, \& Bielajew, 2010). Thus, the genes pointed to be probably involved on paternal care, and derived from animal studies, must be interpreted with some caveats, opening the possibility that such molecular basis of parental behavior in rodents are not necessarily the same in humans.

Despite the limitations stated above, we could conclude about the complexity of biological processes of paternal care. Neural imaging and hormonal data inform about the dynamics and mechanisms that describe the path followed by each father across the transition to fatherhood. In fact, the patterns of some hormones release and brain areas activation change across time in a synchrony way (Swain et al., 2007), and accompanying the father-infant relationship development (Swain, 2008).

Implicating different levels of neural processing, integrating neuroendocrine system and with a genetic root as support, paternal care developed so high complexity probably to increase the quality of father-infant interactions, long-term health of the infant and, ultimately for the human species perpetuation. Adapting Thomas Huxley's argument about the evolution of species, we would like to finish this article with a provocative thought: We are far from imaging that biological processes exist 'in order' to induce paternal responses, biological substrates exist 'because' paternal responses are necessary, in some way, for human perpetuation - paternal response being not the end, but the condition, of biological processes existence.

\section{References}

Afonso, V. M., King, S., Chatterjee, D., \& Fleming, A. S. (2009). Hormones that increase maternal responsiveness affect accumbal dopaminergic responses to pup- and food- stimuli in the female rat. Hormones and Behavior, 56(1), 11-23. doi:10.1016/j.yhbeh.2009.02.003

Afonso, V. M., King, S. J., Novakov, M., Burton, C. L., \& Fleming, A. S. (2011). Accumbal dopamine function in postpartum rats that were raised without their mothers. Hormones and Behavior, 60(5), 632-643. doi:10.1016/j.yhbeh.2011.08.016

Barry, H., \& Paxson, L. M. (1971). Infancy and early childhood: Cross-cultural codes 2. Ethnology, 10(4), 466-508. Retrieved from http://www.jstor.org/stable/3773177

Behl, C., Widmann, M., Trapp, T., \& Holsboer, F. (1995). 17-[beta] Estradiol protects neurons from oxidative stress- induced cell death in vitro. Biochemical and Biophysical Research Communications, 216(2), 473-482. doi:10.1006/ bbrc. 1995.2647

Beishuizen, A., \& Thijs, L. G. (2003). Review: Endotoxin and the hypothalamo-pituitary-adrenal (HPA) axis. Journal of Endotoxin Research, 9(1), 3-24. doi:10.1177/09680519030 090010101

Benaches, M. J. L. (2010). Vinculaciones afectivas. Apego, amistad y amor. Madrid, España: Pirámide.

Berg, S. J., \& Wynne-Edwards, K. E. (2001). Changes in testosterone, cortisol, and estradiol levels in men becoming fathers. Mayo Clinic Proceeding, 76(6), 582-592. doi:10.1177/0968 0519030090010101

Berg, S. J., \& Wynne-Edwards, K. E. (2002). Salivary hormone concentrations in mothers and fathers becoming parents are not correlated. Hormones and Behavior, 42(4), 424-436. doi:10.1006/hbeh.2002.1841

Bosch, O., Pfortsch, J., Beiderbeck, D., Landgraf, R., \& Neumann, I. (2010). Maternal behaviour is associated with vasopressin release in the medial preoptic area and bed nucleus of the stria terminalis in the rat. Journal of Neuroendocrinology, 22(5), 420-429. doi:10.1111/j.1365-2826.2010.01984.x

Brown, J. R., Ye, H., Bronson, R. T., Dikkes, P., \& Greenberg, M. E. (1996). A defect in nurturing in mice lacking the immediate early gene fosB. Cell, 86(2), 297-309. doi:10.1016/ S0092-8674(00)80101-4

Carter, C. S. (1998). Neuroendocrine perspectives on social attachment and love. Psychoneuroendocrinology, 23(8), 779-818. doi:10.1016/S0306-4530(98)00055-9

Carter, C. S. (2007). Sex differences in oxytocin and vasopressin: Implications for autism spectrum disorders? Behavioural Brain Research, 176(1), 170-186. doi:10.1016/j. bbr.2006.08.025

Cerqueira, J. J., Mailliet, F., Almeida, O. F. X., Jay, T. M., \& Sousa, N. (2007). The prefrontal cortex as a key target of the maladaptive response to stress. The Journal of Neuroscience, 27(11), 2781-2787. doi:10.1523/JNEUROSCI.4372-06.2007

Charoenphandhu, N., Wongdee, K., \& Krishnamra, N. (2010). Is prolactin the cardinal calciotropic maternal hormone? Trends in Endocrinology \& Metabolism, 21(7), 395-401. doi:10.1016/j.tem.2010.02.002

Childs, E., Van Dam, N. T., \& Wit, H. D. (2010). Effects of acute progesterone administration upon responses to acute psychosocial stress in men. Experimental and Clinical Psychopharmacology, 18(1), 78. doi:10.1037/a0018060

Clark, M. M., \& Galef, B. G., Jr. (1999). A testosterone-mediated trade-off between parental and sexual effort in male Mongolian gerbils Meriones unguiculatus. Journal of Comparative Psychology, 113(4), 388. doi:10.1037/0735-7036.113.4.388

Clark, M. M., \& Galef, B. G., Jr. (2000). Why some male Mongolian gerbils may help at the nest: Testosterone, asexuality and alloparenting. Animal Behaviour, 59(4), 801-806. doi:10.1006/anbe.1999.1365

Corter, C. M., \& Fleming, A. S. (2002). Psychobiology of maternal behavior in human beings. In M. H. Bornstein (Ed.), Handbook of parenting: Vol. 2. Biology and ecology of parenting ( $2^{\text {nd }}$ ed., pp. 141-181). Mahwah, NJ: Erlbaum.

Davis, M., \& Whalen, P. J. (2001). The amygdala: Vigilance and emotion. Molecular Psychiatry, 6(1), 13-34. Retrieved from http://www.milineafacil.com/2011/06/amygdala-vigilanceand-emotion.html

De Bellis, M. D., Gold, P. W., Geracioti, T. D., Listwak, S. J., \& Kling, M. A. (1993). Association of fluoxetine treatment with reductions in CSF concentrations of corticotropin-releasing 
hormone and arginine vasopressin in patients with major depression. American Journal of Psychiatry, 150, 656-657.

Domes, G., Heinrichs, M., Glascher, J., Buchel, C., Braus, D. F., \& Herpertz, S. C. (2007). Oxytocin attenuates amygdala responses to emotional faces regardless of valence. Biological Psychiatry, 62(10), 1187-1190. doi:10.1016/j. biopsych.2007.03.025

Ducros, L., Vicaut, E., Soleil, C., Le Guen, M., Gueye, P., Poussant, T., ...Plaisance, P. (2010). Effect of the addition of vasopressin or vasopressin plus nitroglycerin to epinephrine on arterial blood pressure during cardiopulmonary resuscitation in humans. The Journal of Emergency Medicine, 41(5), 453-459. doi:10.1016/j.jemermed.2010.02.030

Ellison, P. T., \& Ellison, P. T. (2009). On fertile ground: A natural history of human reproduction. Cambridge, MA: Harvard University Press.

Feldman, R., Gordon, I., Schneiderman, I., Weisman, O., \& Zagoory-Sharon, O. (2010). Natural variations in maternal and paternal care are associated with systematic changes in oxytocin following parent-infant contact. Psychoneuroendocrinology, 35(8), 1133-1141. doi:10.1016/j.yhbeh.2010.06.005

Feldman, R., Gordon, I., \& Zagoory-Sharon, O. (2010). The cross-generation transmission of oxytocin in humans. Hormones and Behavior, 58(4), 669-676.

Fernandez-Duque, E., Valeggia, C. R., \& Mendoza, S. P. (2009). The biology of paternal care in human and nonhuman primates. Annual Review of Anthropology, 38, 115-130. doi:10.1146/annurev-anthro-091908-164334

Ferris, C. F. (1996). Serotonin diminishes aggression by suppressing the activity of the vasopressin system. Annals of the New York Academy Science, 794, 98-103. doi:10.1111/j.1749-6632.1996.tb32513.x

Figueiredo, B. (2004). Depressão na gravidez: Quais as consequências para a mãe e o bebé? In I. Leal \& C. Faria (Eds.), Psicologia da gravidez e da parentalidade (pp. 23-47). Lisboa, Portugal: Fim de Século.

Figueiredo, B., \& Conde, A. (2011). Anxiety and depression symptoms in women and men from early pregnancy to 3-months postpartum: Parity differences and effects. Journal of Affective Disorders, 132(1-2), 146-157. doi:10.1016/j. jad.2011.02.007

Fink, S., Excoffier, L., \& Heckel, G. (2006). Mammalian monogamy is not controlled by a single gene. Proceedings of the National Academy of Sciences, 103(29), 10956-10960. doi:10.1073/pnas.0602380103

Fleming, A. S., Corter, C., Stallings, J., \& Steiner, M. (2002). Testosterone and prolactin are associated with emotional responses to infant cries in new fathers. Hormones and Behavior, 42(4), 399-413. doi:10.1006/hbeh.2002.1840

Gallagher, H. L., \& Frith, C. D. (2003). Functional imaging of 'theory of mind'. Trends in Cognitive Sciences, 7(2), 77-83. doi:10.1016/S1364-6613(02)00025-6

Gammie, S. C., \& Nelson, R. J. (1999). Maternal aggression is reduced in neuronal nitric oxide synthase-deficient mice. The Journal of Neuroscience, 19(18), 8027-8035.

Gettler, L. T., Mcdade, T. W., Agustin, S. S., \& Kuzawa, C. W. (2013). Progesterone and estrogen responsiveness to fathertoddler interaction. American Journal of Human Biology, 25(4), 491-498. doi:10.1002/ajhb.21187

Gettler, L. T., McDade, T. W., Feranil, A. B., \& Kuzawa, C. W. (2011). Longitudinal evidence that fatherhood decreases testosterone in human males. Proceedings of the National Academy of Sciences, 108(39), 16194-16199. doi:10.1073/ pnas. 1105403108
Gettler, L. T., Mcdade, T. W., \& Kuzawa, C. W. (2011). Cortisol and testosterone in Filipino young adult men: Evidence for co-regulation of both hormones by fatherhood and relationship status. American Journal of Human Biology, 23(5), 609-620. doi:10.1002/ajhb.21187

Gonzalez, A., Jenkins, J. M., Steiner, M., \& Fleming, A. S. (2012). Maternal early life experiences and parenting: The mediating role of cortisol and executive function. Journal of the American Academy of Child Adolescent Psychiatry, 51(7), 673-682. doi:10.1016/j.jaac.2012.04.003

Gordon, I., Zagoory-Sharon, O., Leckman, J. F., \& Feldman, R. (2010a). Prolactin, oxytocin, and the development of paternal behavior across the first six months of fatherhood. Hormones and Behavior, 58(3), 513-518. doi:10.1016/j. yhbeh.2010.04.007

Gordon, I., Zagoory-Sharon, O., Leckman, J. F., \& Feldman, R. (2010b). Oxytocin and the development of parenting in humans. Biological Psychiatry, 68(4), 377-382. doi:10.1016/j. biopsych.2010.02.005

Granata, A. R., Pugni, V., Rochira, V., Zirilli, L., \& Carani, C. (2012). Hormonal regulation of male sexual desire: The role of testosterone, estrogen, prolactin, oxytocin, vasopressin, and others. Hormonal Therapy for Male Sexual Dysfunction, 72-82. doi:10.1002/9781119963820.ch6

Gray, P. B., \& Anderson, K. G. (2010). Fatherhood: Evolution and human paternal behavior. Cambridge, MA: Harvard University Press.

Gray, P. B., Parkin, J., \& Samms-Vaughan, M. (2007). Hormonal correlates of human paternal interactions: A hospital-based investigation in urban Jamaica. Hormones and Behavior, 52(4), 499-507. doi:10.1016/j.yhbeh.2007.07.005

Gregg, C., \& Weiss, S. (2012). U.S. Patent No. 20120064028. Pregnancy-induced oligodendrocyte precursor cell proliferation regulated by Prolactin. Washington, DC: U.S. Patent and Trademark Office.

Hammock, E. A. D., \& Young, L. J. (2005). Microsatellite instability generates diversity in brain and sociobehavioral traits. Science, 308(5728), 1630-1634. doi:10.1126/science.1111427

Hulshoff, H. E., Cohen-Kettenis, P. T., van Haren, N. E., Peper, J. S., Brans, R. G., Cahn, W., ...Kahn, R. S. (2006). Changing your sex changes your brain: Influences of testosterone and estrogen on adult human brain structure. European Journal of Endocrinology, 155(1), S107-S114. doi:10.1530/eje.1.02248

Kentner, A. C., Abizaid, A., \& Bielajew, C. (2010). Modeling dad: Animal models of paternal behavior. Neuroscience \& Biobehavioral Reviews, 34(3), 438-451. doi:10.1016/j.neubiorev.2009.08.010

Kleiman, D. G., \& Malcolm, J. R. (1981). The evolution of male parental investment in mammals. Evolution, 1(1970), 347-387.

Kuroda, K. O., Tachikawa, K., Yoshida, S., Tsuneoka, Y., \& Numan, M. (2011). Neuromolecular basis of parental behavior in laboratory mice and rats: With special emphasis on technical issues of using mouse genetics. Progress in Neuro-Psychopharmacology and Biological Psychiatry, 35(5), 1205-1231. doi:10.1016/j.pnpbp.2011.02.008

Kuzawa, C. W., Gettler, L. T., Muller, M. N., McDade, T. W., \& Feranil, A. B. (2009). Fatherhood, pairbonding and testosterone in the Philippines. Hormones and Behavior, 56(4), 429-435. doi:10.1016/j.yhbeh.2009.07.010

Leckman, J. F., \& Herman, A. E. (2002). Maternal behavior and developmental psychopathology. Biological Psychiatry, 51(1), 27-43. doi:10.1016/S0006-3223(01)01277-X 
Lefebvre, L., Viville, S., Barton, S. C., Ishino, F., Keverne, E. B., \& Surani, M. A. (1998). Abnormal maternal behaviour and growth retardation associated with loss of the imprinted gene Mest. Nature Genetics, 20, 163-170. doi:10.1038/2464

Li, L. L., Keverne, E., Aparicio, S., Ishino, F., Barton, S., \& Surani, M. (1999). Regulation of maternal behavior and offspring growth by paternally expressed Peg3. Science, 284(5412), 330-334. doi:10.1126/science.284.5412.330

Lim, M. M., \& Young, L. J. (2006). Neuropeptidergic regulation of affiliative behavior and social bonding in animals. Hormones and Behavior, 50(4), 506-517. doi:10.1016/j. yhbeh.2006.06.028

Liu, J., Sharma, N., Zheng, W., Ji, H., Tam, H., Wu, X., ...Verbalis, J. G. (2011). Sex differences in vasopressin V2 receptor expression and vasopressin-induced antidiuresis. American Journal of Physiology-Renal Physiology, 300(2), 433-440. doi:10.1152/ajprenal.00199.2010

Lommatzsch, M., Hornych, K., Zingler, C., Schuff-Werner, P., Hoppner, J., \& Virchow, J. C. (2006). Maternal serum concentrations of BDNF and depression in the perinatal period. Psychoneuroendocrinology, 31(3), 388-394. doi:10.1016/j. psyneuen.2005.09.003

Lonstein, J. S. (2002). Effects of dopamine receptor antagonism with haloperidol on nurturing behavior in the biparental prairie vole. Pharmacology Biochemistry and Behavior, 74(1), 11-19. doi:10.1016/S0091-3057(02)00952-8

Lorberbaum, J. P., Newman, J. D., Dubno, J. R., Horwitz, A. R., Nahas, Z., Teneback, C. C., ...George, M. S. (1999). Feasibility of using fMRI to study mothers responding to infant cries. Depression and Anxiety, 10(3), 99-104. doi:10.1002/ (SICI)1520-6394(1999)10:3<99::AID-DA2>3.0.CO;2-\#

Lorberbaum, J. P., Newman, J. D., Horwitz, A. R., Dubno, J. R., Lydiard, R. B., Hamner, M. B., ...George, M. S. (2002). A potential role for thalamocingulate circuitry in human maternal behavior. Biological Psychiatry, 51(6), 431-445. doi:10.1016/S0006-3223(01)01284-7

Lubahn, D. B., Moyer, J. S., Golding, T. S., Couse, J. F., Korach, K. S., \& Smithies, O. (1993). Alteration of reproductive function but not prenatal sexual development after insertional disruption of the mouse estrogen receptor gene. Proceedings of the National Academy of Sciences, 90(23), 11162-11166.

Maestripieri, D., \& Zehr, J. L. (1998). Maternal responsiveness increases during pregnancy and after estrogen treatment in macaques. Hormones and Behavior, 34(3), 223-230. doi:10.1006/hbeh.1998.1470

Murray, L., Halligan, S., \& Cooper, P. (2010). Effects of postnatal depression on mother-infant interactions and child development. In J. G. Bremner \& T. D. Wachs (Eds.), The Wiley, Blackwell Handbook of Infant Development $\left(2^{\text {nd }}\right.$ ed., Vol. 2, pp. 192-220). Oxford, UK: Wiley-Blackwell. doi:10.1002/9781444327588.ch8

Nishimori, K., Young, L. J., Guo, Q., Wang, Z., Insel, T. R., \& Matzuk, M. M. (1996). Oxytocin is required for nursing but is not essential for parturition or reproductive behavior. Proceedings of the National Academy of Sciences, 93(21), 11699.

Nissen, E., Gustavsson, P., Widstrom, A., \& Uvnäs-Moberg, K. (1998). Oxytocin, prolactin, milk production and their relationship with personality traits in women after vaginal delivery or Cesarean section. Journal of Psychosomatic Obstetrics \& Gynecology, 19(1), 49-58.

Noriuchi, M., Kikuchi, Y., \& Senoo, A. (2008). The functional neuroanatomy of maternal love: Mother's response to infant's attachment behaviors. Biological Psychiatry, 63(4), 415-423. doi:10.1016/j.biopsych.2007.05.018
Numan, M., \& Insel, T. R. (2003). The neurobiology of parental behavior. New York: Springer.

Nunes-Costa, R. (2010). A multidimensional analysis of maternal separation impact: Corticosteroids and oxytocin linkage (Unpublished master's thesis). Universidade do Minho, Braga, Portugal.

O'Donnell, P. (2005). Mesolimbic-mesocortical loops may encode saliency, not just reward. Behavioral and Brain Science, 28, 360-361. Retrieved from http://philpapers.org/rec/ODOMLM

Olazabal, D., Abercrombie, E., Rosenblatt, J., \& Morrell, J. (2004). The content of dopamine, serotonin, and their metabolites in the neural circuit that mediates maternal behavior in juvenile and adult rats. Brain Research Bulletin, 63(4), 259-268. doi:10.1016/j.brainresbull.2004.02.009

Ostlund, S. B., Wassum, K. M., Murphy, N. P., Balleine, B. W., \& Maidment, N. T. (2011). Extracellular dopamine levels in striatal subregions track shifts in motivation and response cost during instrumental conditioning. The Journal of Neuroscience, 31(1), 200-207. doi:10.1523/JNEUROSCI.4759-10.2011

Parker, K. J., Kinney, L. F., Phillips, K. M., \& Lee, T. M. (2001). Paternal behavior is associated with central neurohormone receptor binding patterns in meadow voles Microtus pennsylvanicus. Behavioral Neuroscience, 115(6), 1341. doi:10.1037/0735-7044.115.6.1341

Paulson, J. F., Dauber, S., \& Leiferman, J. A. (2006). Individual and combined effects of postpartum depression in mothers and fathers on parenting behavior. Pediatrics, 118, 659-668. doi:10.1542/peds.2005-2948

Perini, T., Ditzen, B., Fischbacher, S., \& Ehlert, U. (2012). Testosterone and relationship quality across the transition to fatherhood. Biological Psychology, 90(3), 186-191. doi:10.1016/j.biopsycho.2012.03.004

Perrigo, G., Belvin, L., \& Vom Saal, F. S. (1991). Individual variation in the neural timing of infanticide and parental behavior in male house mice. Physiology \& Behavior, 50(2), 287-296. doi:10.1016/0031-9384(91)90068-Y

Phillips, M. L., Williams, L. M., Heining, M., Herba, C. M., Russell, T., Andrew, C., ...Gray, J. A. (2004). Differential neural responses to overt and covert presentations of facial expressions of fear and disgust. Neuroimage, 21(4), 14841496. doi:10.1016/j.neuroimage.2003.12.013

Pleck, J. H. (2010). Paternal involvement: Revised conceptualization and theoretical linkages with child outcomes. In M. E. Lamb (Ed.), The role of the father in child development $\left(5^{\text {th }}\right.$ ed., pp. 58-93). Hoboken, NJ: John Wiley \& Sons.

Ranote, S., Elliott, R., Abel, K., Mitchell, R., Deakin, J., \& Appleby, L. (2004). The neural basis of maternal responsiveness to infants: An fMRI study. Neuroreport, 15(11), 1825.

Reburn, C. J., \& Wynne-Edwards, K. E. (1999). Hormonal changes in males of a naturally biparental and a uniparental mammal. Hormones and Behavior, 35(2), 163-176. doi:10.1006/hbeh.1998.1509

Rosenblatt, J. (1994). Psychobiology of maternal behavior: Contribution to the clinical understanding of maternal behavior among humans. Acta Paediatrica, 83, 3-8. doi:10.1111/j.1651-2227.1994.tb13259.x

Rosenblatt, J. S., Olufowobi, A., \& Siegel, H. I. (1998). Effects of pregnancy hormones on maternal responsiveness, responsiveness to estrogen stimulation of maternal behavior, and the lordosis response to estrogen stimulation. Hormones and Behavior, 33(2), 104-114. doi:10.1006/hbeh.1998.1441

Russell, J., \& Leng, G. (1998). Sex, parturition and motherhood without oxytocin? Journal of Endocrinology, 157(3), 343-359. doi:10.1677/joe. 0.1570343 
Saydoff, J., Rittenhouse, P., Van de Kar, L., \& Brownfield, M. (1991). Enhanced serotonergic transmission stimulates oxytocin secretion in conscious male rats. Journal of Pharmacology and Experimental Therapeutics, 257(1), 95-99.

Schradin, C., \& Anzenberger, G. (1999). Prolactin, the hormone of paternity. News in Physiological Sciences, 14, 223-230.

Schum, J. E., \& Wynne-Edwards. K. E. (2005). Estradiol and progesterone in paternal and non-paternal hamsters (Phodopus) becoming fathers: Conflict with hypothesized roles. Hormones and Behavior, 47, 410-418. doi:10.1016/j.yhbeh.2004.11.009

Seifritz, E., Esposito, F., Neuhoff, J. G., Lethi, A., Mustovic, H., Dammann, G., ...Di Salle, F. (2003). Differential sex-independent amygdala response to infant crying and laughing in parents versus nonparents. Biological Psychiatry, 54(12), 1367-1375. doi:10.1016/S0006-3223(03)00697-8

Shahrokh, D. K., Zhang, T. Y., Diorio, J., Gratton, A., \& Meaney, M. J. (2010). Oxytocin-dopamine interactions mediate variations in maternal behavior in the rat. Endocrinology, 151(5), 2276-2286. doi:http://dx.doi.org/10.1210/en.2009-1271

Share, L., Crofton, J. T., \& Ouchi, Y. (1988). Vasopressin: Sexual dimorphism in secretion, cardiovascular actions and hypertension. The American Journal of the Medical Sciences, 295(4), 314.

Storey, A. E., Noseworthy, D. E., Delahunty, K. M., Halfyard, S. J., \& McKay, D. W. (2011). The effects of social context on the hormonal and behavioral responsiveness of human fathers. Hormones and Behavior, 60, 353-361. doi:10.1016/j. yhbeh.2011.07.001

Storey, A. E., Walsh, C. J., Quinton, R. L., \& Wynne-Edwards, K. E. (2000). Hormonal correlates of paternal responsiveness in new and expectant fathers. Evolution and Human Behavior, 21(2), 79-95. doi:10.1016/S1090-5138(99)00042-2

Strathearn, L., Li, J., \& Montague, P. (2005). An fMRI study of maternal mentalization: Having the baby's mind in mind. Neuroimage, 26(Suppl. 1), S25.

Swain, J. E. (2008). Baby stimuli and the parent brain: Functional neuroimaging of the neural substrates of parent-infant attachment. Psychiatry (Edgmont), 5(8), 28.

Swain, J. E. (2011). The human parental brain: In vivo neuroimaging. Progress in Neuro-Psychopharmacology \& Biological Psychiatry, 35, 1242-1254. doi:10.1016/j.pnpbp.2010.10.017

Swain, J. E., Leckman, J. F., Mayes, L. C., Feldman, R., Constable, R. T., \& Schultz, R. T. (2003). The neural circuitry of parent-infant attachment in the early postpartum. Paper presented at the American College of Neuropsychopharmacology $42^{\text {nd }}$ Annual Meeting, San Juan, Puerto Rico.

Swain, J. E., Leckman, J. F., Mayes, L. C., Feldman, R., Constable, R. T., \& Schultz, R. T. (2004). Neural substrates and psychology of human parent-infant attachment in the postpartum. Biology Psychiatry, 55(8), 153S

Swain, J. E., Leckman, J. F., Mayes, L. C., Feldman, R., \& Schultz, R. T. (2005). Early Human Parent-Infant bond development: fMRI, thoughts and behaviors. Biology Psychiatry, 57(8), 112S.

Swain, J. E., Lorberbaum, J. P., Kose, S., \& Strathearn, L. (2007). Brain basis of early parent-infant interactions: Psychology, physiology, and in vivo functional neuroimaging studies. Journal of Child Psychology and Psychiatry, 48(4), 262-287. doi:10.1111/j.1469-7610.2007.01731.x

Taber, K. H., Black, D. N., Porrino, L. J., \& Hurley, R. A. (2012). Neuroanatomy of dopamine: Reward and addiction. The Journal of Neuropsychiatry and Clinical Neurosciences, 24(1), 1-4. doi:10.1176/appi.neuropsych.24.1.1
Thomas, S. A., \& Palmiter, R. D. (1997). Thermoregulatory and metabolic phenotypes of mice lacking noradrenaline and adrenaline. Nature, 387, 94-97. doi:10.1038/387094a0

Trainor, B. C., Bird, I. M., Alday, N. A., Schlinger, B. A., \& Marler, C. A. (2003). Variation in aromatase activity in the medial preoptic area and plasma progesterone is associated with the onset of paternal behavior. Neuroendocrinology, 78, 36-44. doi:10.1159/000071704

Uvnäs-Moberg, K. (1998). Oxytocin may mediate the benefits of positive social interaction and emotions. Psychoneuroendocrinology, 23(8), 819-835. doi:10.1016/S0306-4530(98)00056-0

Uvnäs-Moberg, K., Ahlenius, S., Alster, P., \& Hillegaart, V. (1996). Effects of selective serotonin and dopamine agonists on plasma levels of glucose, insulin and glucagon in the rat. Neuroendocrinology, 63(3), 269-274. doi:10.1159/000126970

van Anders, S. M., Tolman, R. M., \& Volling, B. L. (2011). Baby cries and nurturance affect testosterone in men. Hormones and Behavior, 61(1), 31-36. doi:10.1016/j.yhbeh.2011.09.012

Villalba, C., Boyle, P. A., Caliguri, E. J., \& De Vries, G. J. (1997). Effects of the selective serotonin reuptake inhibitor fluoxetine on social behaviors in male and female prairie voles (Microtus ochrogaster). Hormones and Behavior, 32(3), 184-191. doi:10.1006/hbeh.1997.1420

Vogel, F., Wagner, S., Baskaya, N., Leuenberger, B., Mobascher, A., Dahmen, N., ...Tadić, A. (2012). Variable number of tandem repeat polymorphisms of the arginine vasopressin receptor $1 \mathrm{~A}$ gene and impulsive aggression in patients with borderline personality disorder. Psychiatric Genetics, 22(2), 105. doi:10.1097/YPG.0b013e32834accad

Walum, H., Westberg, L., Henningsson, S., Neiderhiser, J. M., Reiss, D., Igl, W., ...Lichtenstein, P. (2008). Genetic variation in the vasopressin receptor la gene (AVPR1A) associates with pair-bonding behavior in humans. Proceedings of the National Academy of Sciences, 105(37), 14153-14156. doi:10.1073/ pnas.0803081105

Wehr, R., Mansouri, A., de Maeyer, T., \& Gruss, P. (1997). Fkh5-deficient mice show dysgenesis in the caudal midbrain and hypothalamic mammillary body. Development, 124(22), 4447-4456.

Williamson, P. (2006). Mind, brain and schizophrenia. Oxford, UK: Oxford University Press.

Wirth, M. M. (2011). Beyond the HPA axis: Progesterone derived neuroactive steroids in human stress and emotion. Frontiers in Endocrinology, 2, 1-14. doi:10.3389/fendo.2011.00019

Wynne-Edwards, K. E. (1998). Evolution of parental care in Phodopus: Conflict between adaptations for survival and adaptations for rapid reproduction. American Zoologist, 38(1), 238-250. doi:10.1093/icb/38.1.238

Wynne-Edwards, K. E., \& Timonin, M. E. (2007). Paternal care in rodents: Weakening support for hormonal regulation of the transition to behavioral fatherhood in rodent animal models of biparental care. Hormones and Behavior, 52(1), 114-121. doi:10.1016/j.yhbeh.2007.03.018

Ziegler, T. E., \& Snowdon, C. T. (2000). Preparental hormone levels and parenting experience in male cotton-top tamarins, Saguinus oedipus. Hormones and Behavior, 38(3), 159-167. doi:10.1006/hbeh.2000.1617 